\title{
Calculation of aerodynamic characteristics of flying objects using Prodas and Fluent environments
}

\author{
Obliczanie charakterystyk aerodynamicznych obiektów latających \\ z wykorzystaniem programów Prodas i Fluent
}

\author{
LESZEK BARANOWSKI \\ MICHAt FRANT*
}

DOI: https://doi.org/10.17814/mechanik.2017.7.82

\begin{abstract}
The article presents the methodology of determining the basic aerodynamic characteristics using the Fluent theoretical method and the theoretical and experimental method using the Prodas program. Presented calculations were made for a $122 \mathrm{~mm}$ non-guided missile. In order to compare both methods, the results of calculations of coefficient of drag force, lift force coefficient and pitching moment coefficient as a function of incidence angle of attack (AoA) and Mach number are shown in graphs.
\end{abstract}

\section{KEYWORDS: fluid mechanics, CFD, Fluent, Prodas}

The concept of aerodynamic characteristics of a flying object (FO) is understood as the coefficients of forces and moments of the aerodynamic forces acting on the FO moving in the earth's atmosphere. Aerodynamic characteristics can be determined by strictly theoretical, theoretical-experimental, and experimental methods. Theoretical methods rely primarily on determining the movement of fluid in the vicinity of the flowing body and come down to the solution of the basic problem of fluid mechanics Navier-Stokes equations. For this purpose, programs can be used to solve problems related to fluid mechanics, called CFD (computational fluid dynamics). Theoretical-experimental methods consist in the calculation of the aerodynamic characteristics of the whole FO based on the set of experimentally determined aerodynamic characteristics of its isolated elements, taking into account their mutual position along the hull and the aerodynamic interaction (interference) of these parts. In the case of experimental methods, the basis for determination of aerodynamic characteristics of $\mathrm{FO}$ is the knowledge of aerodynamic forces and moments acting on the object in free flight. Aerodynamic forces and moments can be determined by direct methods (e.g. in a wind tunnel) or indirect - on the basis of the measured object in the flight trajectory of a plurality of points [1].

\footnotetext{
* Dr hab. inż. Leszek Baranowski, prof. WAT

(leszek.baranowski@wat.edu.pl) - Katedra Mechatroniki, Wydział Mechatroniki i Lotnictwa Wojskowej Akademii Technicznej; mjr dr inż. Michał Frant (michal.frant@wat.edu.pl) - Instytut Techniki Lotniczej, Wydział Mechatroniki i Lotnictwa Wojskowej Akademii Technicznej
}

The article tested the theoretical possibilities using the Fluent software and the theoretical-experimental method using the Prodas software. For this purpose, determined $122 \mathrm{~mm}$ aerodynamic characteristics of the missile Phoenix with a shattering head (fig. 1).

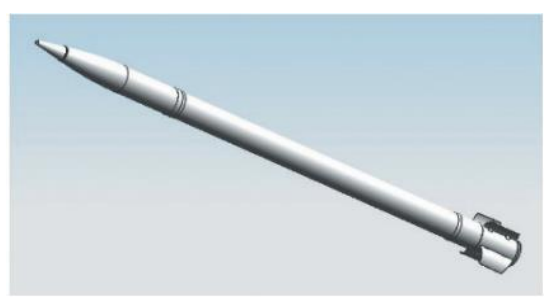

Fig. 1. Solid model of the $122 \mathrm{~mm}$ Phoenix missile, developed in the SolidWorks environment

Taking advantage of the capabilities of the Fluent software

The process of determining the aerodynamic characteristics of the FO in the Fluent CFD involves the following steps:

- generation the a solid model and prepare the geometry for discretization,

- digitization of the object and computational domain,

- performing calculations of flow around the object for given flow parameters, e.g. specific Mach numbers,

- calculating the coefficients of determination of aerodynamic FO forces and moments.

In the example under consideration, the object was discretized using a triangular mesh, while the surrounding area of the missile was surrounded by two grids:

- tetrahedral (with 755,681 elements) thickened in the vicinity of the examined object - it was used to verify the correctness of selected boundary conditions and the size of the area surrounding the computational domain (fig. 2a),

- hybrid (with 3383364 elements), consisting of five layers of prismatic elements in the boundary layer and tetrahedral grid in the remaining area, because hybrid mesh calculations generally produce more accurate results than tetrahedral mesh [2] (fig. 2b).
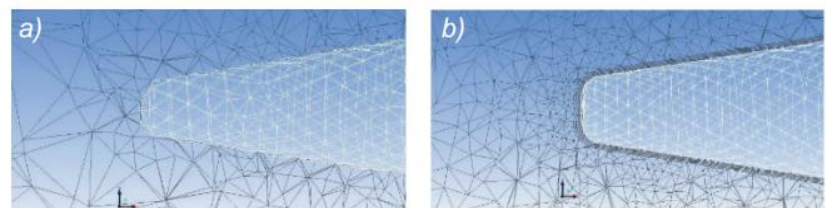

Fig. 2. The boundary layer discretized by grid: a) tetrahedral, b) hybrid 
The following boundary conditions were used in calculations:

on the bullet - "wall" condition [3],

- on the surface surrounding the computational domain the condition "pressure far field" [3] (computational domain was ideal gas).

Determining the initial conditions allowed for the calculation of the flow parameters of the examined object for selected Mach numbers and angles of attack (AoA). Fluent package used for this purpose finite volume method, which consists of a direct physical space discretization equations expressing conduct, because the starting point is the conservation equations in the form of integration. Subsequently, these equations are subjected to averaging operation in accordance with the formulas given in [4, 5] - thus obtained equation known as Reynolds equations. It should be noted that the averaging of equations causes the closed system of equations to become open system - there are no six complementary compounds defining the components of the turbulent stress tensor [5]. Thus, there is the need for turbulence models. During the study aerodynamic missile Phoenix turbulence model $k$ $\varepsilon$, or more precisely - its improved version known as the "realizable" $k-\varepsilon$ [6], the most commonly used and accepted values of the constants model [7].

Performed calculations can be illustrated using raster charts representing the change of any flow parameter. For example, raster graphs of static pressure changes for projectile flow at $\mathrm{Ma}=3.5$ at AoA $\alpha=0^{\circ}$ (fig. 3a) and $\alpha=2^{\circ}$ (fig. $3 b$ ).

a)

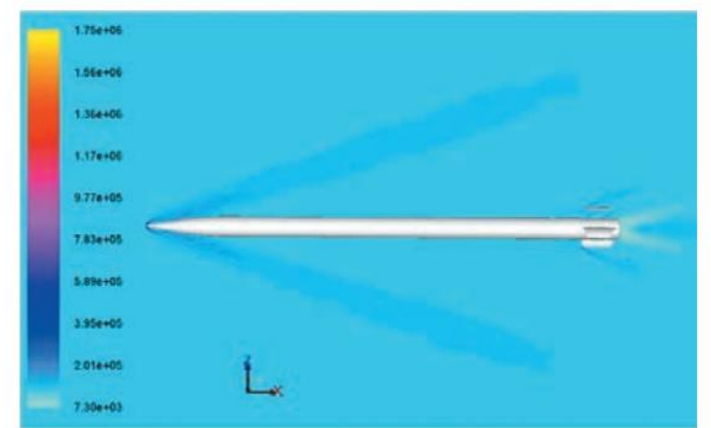

b)

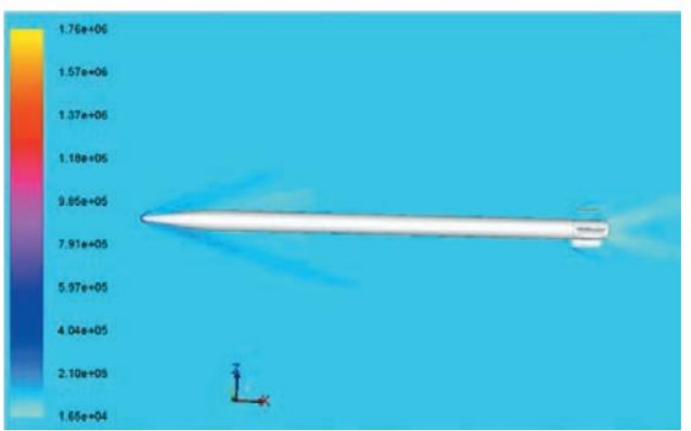

Fig. 3. Static pressure distribution at the Phoenix missile at $\mathrm{Ma}$ $=3.5$ and at the AoA: a) $\alpha=0^{\circ}$, b) $\alpha=2^{\circ}$

\section{Taking advantage of the capabilities of Prodas software}

The Prodas ver. 3.5.3 [8] is a specialized tool for broadly understood computer-aided design of munitions, including calculation of the aerodynamic characteristics of the FO.

In order to determine the aerodynamic characteristics of FO, it is necessary first to generate a geometric model of this object. For this purpose, the Visual Model Editor [9] was used. The size of each component of the object are introduced by dividing its basic elements (cylinders, cones, and pointed arch).

Each part of the object is attributed to structural function (the structural stabilizer, an explosive cartridge cumulative, tracer). Each base element is also assigned an aerodynamic "function" that defines the nature of the "collaboration" of that element with the medium in which the FO traverses. The program allows to select one of the four available aerodynamic stabilizer wings: rectangular, delta, trapezoid and swept.

The $122 \mathrm{~mm}$ Phoenix (fig. 4) geometry model developed in the Prodas has a simplified stabilizer wing compared to a real missile and a solid model based on it (fig. 1). This is due to the fact that the Prodas software does not provide for such a type of bearing surface (with the same contour as the actual projectile). Therefore, the type of Clipped Delta ballast, that is closest in shape, has been adopted. The dimensions of the simplified flap were chosen in such a way that its surface area, the span and the shape of the front edge were in line with the actual one.

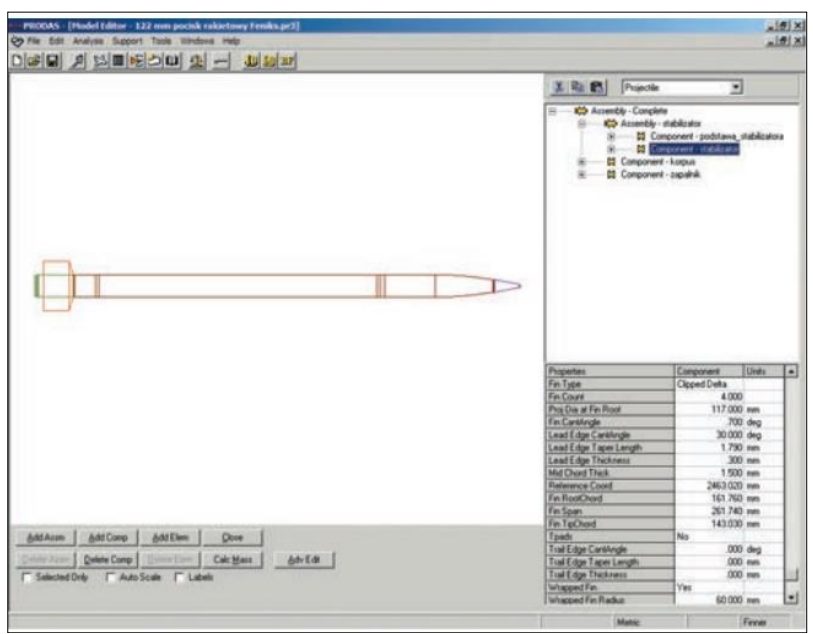

Fig. 4. The Visual Model Editor window for creating a geometry model in Prodas

The aerodynamic model, built on the basis of the geometric model developed, is most often simplified and adapted to the computing capabilities of Prodas. A simplified diagram of this model can be found in the Aero Model tab of the Aero Predictions window (fig. 5). This allows for a visual validation of the model and possible correction of the data entered in the editing module.

A list of aerodynamic coefficients for calculating the aerodynamic characteristics of $\mathrm{FO}$, produced by the Prodas program, with indications conforming to the U.S. convention. Ballistic Army Research Laboratory (BRL) [10], is given in the table.

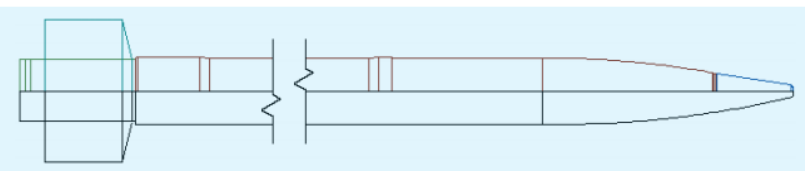

Fig. 5. Graphical representation of the aerodynamic model comparison (bottom section) against its actual shape (upper section) from the Aero Model tab. 
TABLE. List of aerodynamic coefficients calculated by the Mach number using Prodas

\begin{tabular}{|c|c|}
\hline Symbol & Unit \\
\hline$C_{\mathrm{Do}}$ & - \\
\hline$C_{\mathrm{Da} 2}$ & $1 / \mathrm{rad}^{2}$ \\
\hline$C_{\mathrm{La}}$ & $1 / \mathrm{rad}$ \\
\hline$C_{\mathrm{La} 3}$ & $1 / \mathrm{rad}^{3}$ \\
\hline$C_{\text {spin }}$ & - \\
\hline$C_{\mathrm{Ma}}$ & $1 / \mathrm{rad}$ \\
\hline$C_{\mathrm{Ma}}$ & - \\
\hline
\end{tabular}

In order to determine the coefficient of drag force $C_{x}$, coefficient of the lift force $C_{z}$ and coefficient of pitching moment $m_{z}$, the following dependencies were used:

$$
\begin{gathered}
C_{\mathrm{x}}=C_{\mathrm{Do}}+C_{\mathrm{Da} 2} \alpha^{2} \\
C_{\mathrm{z}}=C_{\mathrm{L \alpha}} \alpha+C_{\mathrm{La} 3} \alpha^{3} \\
m_{z}=C_{\mathrm{Ma}} \alpha
\end{gathered}
$$

\section{Comparison of calculation results}

The results of calculation of the aerodynamic characteristics of $122 \mathrm{~mm}$ Phoenix missile obtained from the Fluent and Prodas programs are summarized in figs. 6-8.

The calculations carried out and illustrated in the diagrams confirm the suitability of both programs for determining the aerodynamic characteristics of simple flying objects. Relatively small differences in calculations (up to a maximum of $10 \%$ in the case of the drag coefficient for angle $\alpha=5^{\circ}$ ) may be indicative of the correctness of both programs. The Prodas software is undoubtedly simpler to use and enables faster calculation of the necessary aerodynamic characteristics FO.

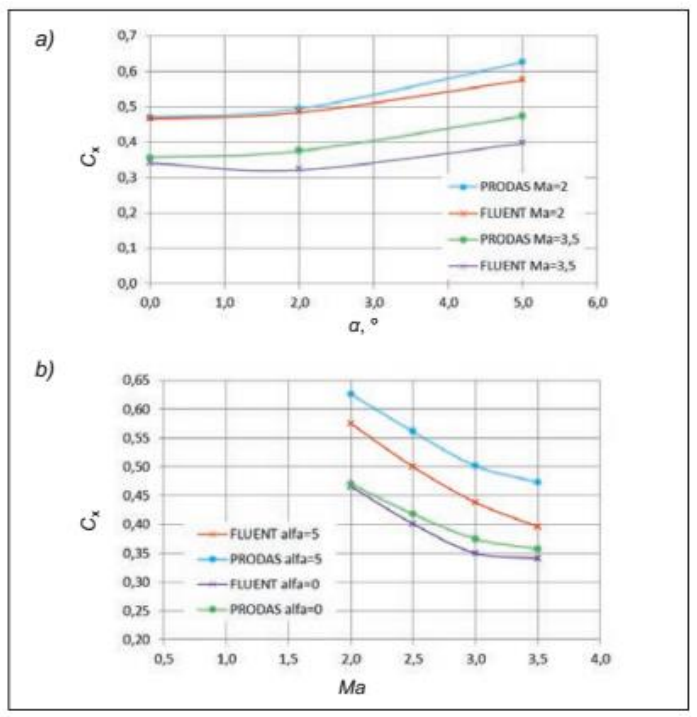

Fig. 6. Graphs of drag force coefficient $C_{x}$ in function of: a) AoA for two Mach numbers $(M a=2$ and $M a=3.5)$, b) Mach numbers for two AoA $\left(\alpha=0^{\circ}\right.$ and $\left.\alpha=5^{\circ}\right)$ a)

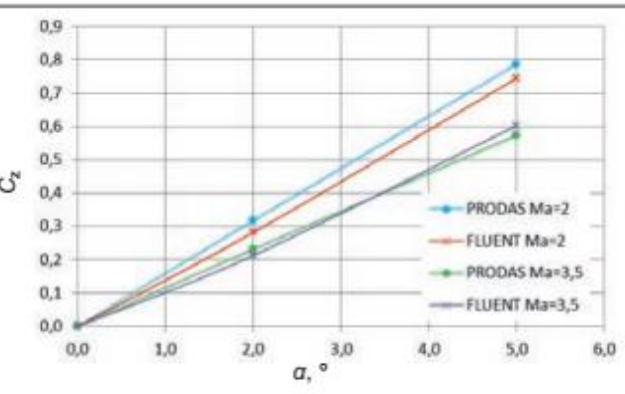

b)

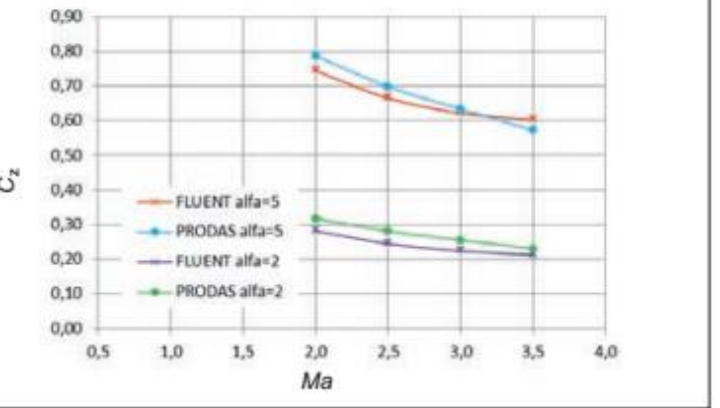

Fig. 7. Graphs of lift force coefficient $C_{z}$ in function of: a) AoA for two Mach numbers $(M a=2$ and $M a=3.5)$, b) Mach numbers for two AoA $\left(\alpha=0^{\circ}\right.$ and $\left.\alpha=5^{\circ}\right)$

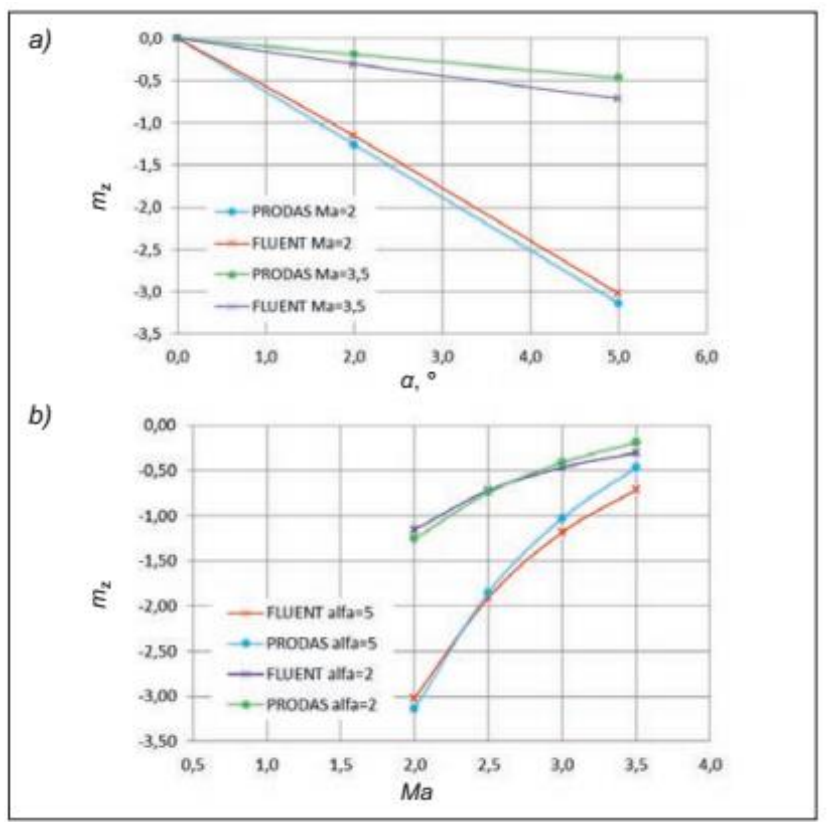

Fig. 8. Graphs of pitching moment coefficient $m_{z}$ in function of: a) AoA for two Mach numbers $(M a=2$ and $M a=3.5)$, b) Mach numbers for two AoA $\left(\alpha=0^{\circ}\right.$ and $\left.\alpha=5^{\circ}\right)$

\section{REFERENCES}

1. Baranowski L. „Modelowanie, identyfikacja i badania numeryczne dynamiki lotu obiektów balistycznych na potrzeby systemów kierowania ogniem artylerii naziemnej”. Rozprawa habilitacyjna. Warszawa: Wyd. WAT, 2011.

2. Frant M. „Numeryczna analiza aerodynamiki złożonych obiektów metoda objętości skończonych". Rozprawa doktorska. Warszawa 2009.

3. Ansys Fluent. User manual.

4. Wilcox D.C. "Turbulence modeling for CFD". 2000.

5. Elsner J.W. „Turbulencja przepływów”. Warszawa: PWN, 1987.

6. Shih T.H., Liou W.W., Shabbir A., Yang Z., Zhu J. "A new k- $\varepsilon$ eddy-viscosity model for high Reynolds number turbulent flows - model development and validation". Computers Fluids. 24, 3 (1995): pp. 227-238.

7. Ferziger J., Perić M. “Computational Methods for Fluid Dynamics". Berlin: Springer, 2002. 
8. Arrow Tech Webside, www.prodas.com.

9. Prodas v3 User manual.

10. McCoy R.L. "Modern Exterior Ballistics. The Launch and

Flight Dynamics of Symmetric Projectiles". Schiffer Publishing, 1999. 